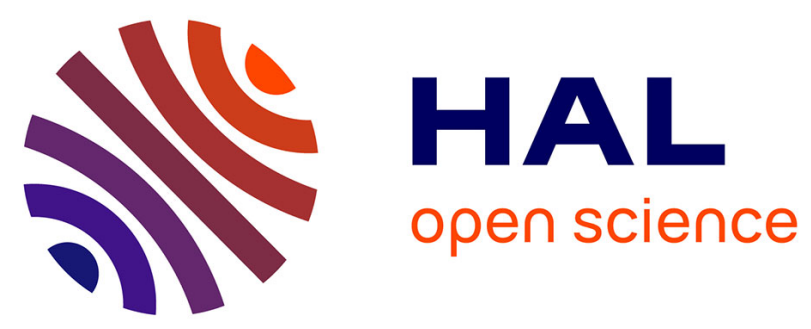

\title{
Additivity and probability
}

Jacques Jayez, Grégoire Winterstein

\section{To cite this version:}

Jacques Jayez, Grégoire Winterstein. Additivity and probability. Lingua, 2013, 132, pp.85-102. 10.1016/j.lingua.2012.11.004 . hal-01069769

\section{HAL Id: hal-01069769 \\ https://hal.science/hal-01069769}

Submitted on 30 Sep 2014

HAL is a multi-disciplinary open access archive for the deposit and dissemination of scientific research documents, whether they are published or not. The documents may come from teaching and research institutions in France or abroad, or from public or private research centers.
L'archive ouverte pluridisciplinaire HAL, est destinée au dépôt et à la diffusion de documents scientifiques de niveau recherche, publiés ou non, émanant des établissements d'enseignement et de recherche français ou étrangers, des laboratoires publics ou privés. 


\title{
Additivity and Probability Jacques Jayez and Grégoire Winterstein
}

\begin{abstract}
In this work, we give a new semantics to the notion of additivity as embodied by several discourse markers and particles in French: et, de plus and d'ailleurs. The common property of these different elements is the notion of independence of their arguments. We show that existing accounts of additive particles fail to do full justice to this notion of independence, and we propose a new semantics for and that captures this notion in a Bayesian fashion. We then evaluate the applicability of this analysis to de plus and d'ailleurs and show that, unlike et, these elements are strongly argumentative: they make an explicit reference to an external issue that is disputed in the current conversation.
\end{abstract}

Keywords: Additivity, Probability, Argumentation, Dependence, Discourse markers

\section{Introduction}

In this paper, we study variations on additivity in French by considering three discourse markers : et, de plus and d'ailleurs. The common theme behind the empirical properties of these three elements is the question of (in) dependence ${ }^{1}$. We try to determine whether these discourse markers impose restrictions on the mutual dependence of the propositions they connect.

\footnotetext{
${ }^{1}$ One could wonder why other seemingly additive markers such as aussi/too or même/even are not considered here (see König 1991). The case of aussi has already been studied in the framework we use here (Winterstein, 2010) and there are various reasons for not including it in this discussion. First, it does not mark independence like the three markers we study here. Second, the fact that it can both combine with et/and and mais/but suggests that it does not belong to the same class as et/and. The case of même/even is even more different because it is not based on (in)dependence either and involves scales.
} 
Dependence is expressed in the framework of probabilistic relevance, in line with Merin's work, essentially because, as explained in the Appendix, this type of framework provides a very flexible tool, which leaves room for a number of variations.

The main result of our investigation is that the markers under study are abstract but not 'minimal', in the sense of having only a bare logical semantics. For instance, contrary to what is sometimes assumed in theoretical linguistics, and is not just 'logical conjunction + pragmatics'. It conveys some non-trivial content, which corresponds to a conventional implicature in the sense of Grice and Potts (2005) and informs discourse structure, in particular by constraining the type of discourse relations that are appropriate. This is even more true for de plus and d'ailleurs, whose conventional content is more complex.

The analysis of additivity we propose leads us to question the (basic meaning + pragmatics enrichment) strategy that has become an implicit or explicit standard in semantics and pragmatics (see Ariel 2008, pp. 71-84 for the case of and). While we do not reject the idea of pragmatic enrichment, we think that one has also to take into account the semantic richness of lexicon, shaped by long periods of evolution, because it is one of the factors that influence enrichment scenarios.

We start with an analysis of et (and), which proves to be the least constrained marker of the three. After reviewing several proposals about its semantics, we point out some of their flaws and propose an improved analysis that crucially relies on a Bayesian interpretation of discourse. Next, the semantics of the marker de plus is compared with that of et/and. It is shown that, when compared to et, de plus restricts the type of its argumentative goal. Finally, we offer a preliminary analysis for d'ailleurs, in order to present a partly different case of additivity, thus illustrating even more clearly the difficulty of directly deriving additivity from pragmatics.

\section{The discourse markers et and and}

This section is focused on the semantics of the French discourse marker et and its English counterpart and. While our conclusions are mainly drawn from the French examples, we believe that these markers are sufficiently similar to assume that they have the same semantic contribution. In essence, we propose that et/and marks the independence of their conjuncts regarding the goal the speaker is trying to defend by making her discourse move. The 
model of discourse that we rely on is explained in detail in the appendix. In particular, the notion of relevance is given a precise definition. In order to motivate our proposal, we first begin by reviewing some influential approaches to and (once again assuming that they apply to et) and we explain the main problems they face.

\subsection{The empirical profile of and}

The semantics of and and its discursive effects have been the subject of extensive study (Schmerling, 1975; Bar-Lev \& Palacas, 1980; Lang, 1984; Carston, 1993; Geurts, 1999; Txurruka, 2003; Blakemore \& Carston, 2005; Zeevat \& Jasinskaja, 2007; Ariel, 2008; Singh, 2008).

These contributions mainly address three kinds of issues:

1. the question of the symmetry of and,

2. its possible 'enrichments', on the basis of a core conjunctive value,

3. the differences that exist between a conjunction with and and asyndetic coordination

We will not discuss asyndetic coordination in this work. Nevertheless, the comparison with it is interesting insofar as it highlights the effect of and on the discourse relations it allows to infer between its conjuncts. So, we occasionally compare structures A and B to structures A B.

\subsubsection{The asymmetry of et/and}

A standard observation about et/and is that, unlike its logical counterpart, it is not a symmetric connective. The usual diagnosis consists in taking an and conjunction, switch its conjuncts around and test whether the inversion yields some change in the interpretation of the whole discourse.

This is illustrated by the pair in (1). In (1a), a RESULT interpretation can be inferred: it's because Paul forgot his passport that he was blocked at the border. This interpretation is dispreferred in (1b), where the two conjuncts can be understood as independent events, forming a temporal sequence or not, or as connected by a reverse causal relation: it's because Paul was blocked that he forgot his passport, maybe because he was upset.

(1) a. Paul a oublié son passeport et il a été bloqué à la frontière par la police.

Paul forgot his passport and he was blocked at the border by the police. 
b. Paul a été bloqué à la frontière par la police et il a oublié son passeport.

Paul was blocked at the border by the police and he forgot his passport.

So, even though both versions in (1) are acceptable discourses, their interpretations differ, showing that the order of the conjuncts of et/and matters.

\subsubsection{And and discourse relations}

Another frequent observation is that it is difficult, or even practically impossible in some cases, to construct discourse relations such as ELABORATION and EXPLANATION with a coordination using et/and. On the other hand, such discourse relations can perfectly be inferred when using plain asyndetic coordination:

a. Paul portait une cravate, (? et) elle était rouge.

Paul wore a tie, (? and) it was a red one.

b. Paul portait une cravate, (?et) il voulait impressionner ses étudiants.

Paul wore a tie, (? and) he wanted to impress his students.

The examples in (2) show that the semantic contribution of et/and cannot be limited to a simple juxtaposition of facts. The basic intuition is that et/and is not natural whenever it conjoins pieces of information that are not independent (Lang, 1984). Since elaborative material usually refers to a proper subpart of a previous utterance's denotation and explanation is not independent of its consequences, this intuition accounts for the difficulty in establishing these discourse relations. However, one might object that the terminology of 'independence' remains loose and provides only little more than a vague and perhaps misleading intuition.

\subsection{Recent approaches to and}

In this section, we present three approaches that address the observations made in the previous section. All of them try to give a formal content to the intuition we formulated above: in a sentence $A$ and $B$, the second conjunct $B$ must not repeat what the first one already said. These approaches face a number of empirical issues that we mention as we present the different accounts. 


\subsubsection{Txurruka (2003): coordination vs. subordination}

The basic intuition of Txurruka (2003)'s account is based on the distinction between coordinating and subordinating discourse relations, as proposed by Polanyi (1985) and developed by Asher \& Lascarides (2003) in the framework of SDRT. Txurruka postulates that and can only express coordinating discourse relations between its first and second conjuncts. Since subordinating discourse relations present their second element as dependent on the first, Txurruka's hypothesis seems an appropriate way to substantiate the intuition formulated above about the semantics of and. Indeed, her proposal readily explains the examples in (1) and (2).

- Since a relation of ExPlanATION is subordinating, it cannot be inferred in (1b): and forces a coordinating relation between its conjuncts, in this case a simple NARRATION. In (1a) the relation is one of RESULT which is coordinating (Asher \& Vieu, 2005) and thus not problematic.

- Both intended relations in (2) are subordinating, and it is difficult to infer a different discourse structure out of a particular context, hence the degraded nature of and. Asyndetic coordination does not share the restrictions of and and allows the inference of these relations.

Another type of observation that fits nicely with Txurruka's proposal is provided by the French marker en effet. En effet can convey a ConfIRMATION (coordinating) or an ExPLANATION (subordinating) relation. Depending on the meaning intended, proper translations would be either indeed (for CONFIRMation) or roughly because (for Explanation). For instance, (3) is potentially ambiguous between two interpretations: 'Paul gave up his exam because he had not worked enough' (ExPLANATION) or 'Paul gave up his exam and people who said that he had not worked much are indeed right' (CONFIRMATION).

(3) Paul a renoncé à passer l'examen; (?et) en effet il n'avait pas beaucoup travaillé.

Paul gave up his exam, (and) EN EFFET he had not worked much.

According to Txurruka, the prediction for the combination of et with en effet is that only the CONFIRMATION reading of en effet will be compatible with et. This prediction appears to be borne out: the use of et in (3) is degraded (where an ExPLANATION is intended), whereas it is fine in (4) where a CONFIRMATION is in order. 
(4) Nous avions choisi ce trek [...] parce qu'il est beaucoup moins fréquenté que ceux des Annapurnas ou de l'Everest. Et en effet, nous avons croisé que quelques touristes.

http://asie. envoyagesurunnuage.net/w/2010/03/21/nepal-trek-langtang-et-gosainkund/

We chose this trek because it is much less popular than Annapurna or Everest. And indeed we met only a few tourists.

However, Txurruka's account also faces empirical problems. In some cases, it seems that and introduces a conjunct attached by a subordinating relation to the left conjunct (the attested examples that follow are in English, but work as well in French):

(5) Measles is back, and it's because your kids aren't vaccinated. http://current.com/news/92737012_measles-is-back-and-its-because-your-kids-arent-vaccinated.htm

Les oreillons sont de retour et c'est parce que vos enfants ne sont pas vaccinés.

It seems difficult to interpret (5) without inferring an EXPLANATION of the first conjunct by the second: the second conjunct includes because which is a marker of ExPLANATION. As already mentioned this relation is subordinating, and should thus be impossible to infer (as in (1b)).

Another problematic example is given in (6).

(6) They got returns by the semi-load! And yet they refused to admit the problem.

http: //www . ihatedell . net/forum/phpBB3/viewtopic $\cdot$ php?f=21\&t=18036

Ils ont eu des retours par wagons et pourtant ils ont refusé d'admettre le problème.

In (6), the status of the discourse relation is debatable. If it turns out that it can be subordinating, then (6) is a counterexample to Txurruka's theory. One way of forcing a subordinating relation is to present the second conjunct as a parenthetical adjunct ${ }^{2}$ :

\footnotetext{
${ }^{2} \mathrm{~A}$ reviewer points out that (7B) might not be as good as (6). Since the French equivalent of (7B) would be perfectly alright, and since other informants did not seem upset by the felicity of (7B), we assume that it serves our point.
} 


$$
\begin{aligned}
& \mathrm{A}-\text { What happened to TechniSnore? } \\
& \mathrm{B}-\text { Well, they got returns by the semi-load-and yet they refused to } \\
& \text { admit the problem-and they had to hire extra people to deal with } \\
& \quad \text { replacements. }
\end{aligned}
$$

The general conclusion about Txurruka's account is that it is not sufficient to explain the distribution of and. Nevertheless, in some cases (namely with French en effet), the distinction between coordinating and subordinating seems to be operational.

\subsubsection{Blakemore 85 Carston (2005): parallel arguments}

And has received several treatments in the framework of Relevance Theory (RT). One of the most recent is proposed by Blakemore \& Carston (2005) and is inspired by previous works, among which (Carston, 1993; Blakemore \& Carston, 1999).

Blakemore and Carston consider that, from an informational point of view, and only encodes a logical conjunction. However, and also encodes a procedural content, i.e. it gives an indication about how its conjuncts must be interpreted under the optimal relevance assumption. ${ }^{3}$ More precisely, and indicates that in a sentence $S_{1}$ and $S_{2}$, the conjuncts $S_{1}$ and $S_{2}$ must play parallel roles in the derivation of the same effect.

The analysis we propose for et/and will be quite close to the analysis proposed in RT, which is expected given that the argumentative approach we assume and the RT framework share many similarities. However, the RT approach faces one problem: by merely stating that the two conjuncts connected by et/and play parallel roles, it predicts that for any sentence of the form $p$ et/and $q$, there should be no difference in acceptability with the reversed sentence $q$ et/and $p$. This is wrong, as can be seen with the pair in (8).
a. Paul a un chien, et c'est un berger allemand.
Paul has a dog, and it's a German shepherd.
b. \# Paul a un berger allemand, et c'est un chien.
Paul has a German shepherd, and it's a dog.

In other terms, as noted, the RT approach gives symmetric roles to both

\footnotetext{
${ }^{3}$ In this respect, it would not be correct to assign to RT approaches the simple view of and as 'logical conjunction + pragmatics' that we have been alluding to in the introduction.
} 
conjuncts, whereas it appears that the first conjunct has an effect on the interpretation of the second one. This is precisely the point that our analysis is intended to capture in an explicit way.

\subsubsection{Zeevat 85 Jasinskaja (2007): additivity by questions}

More recently, Zeevat \& Jasinskaja (2007) (henceforth Z\&J) proposed to treat and as an additive marker, with a notion of additivity rooted in the property of disjointness. Formally their claim is that:

(9) In a sentence $A$ and $B, A$ and $B$ must provide disjoint answers to a common (and possibly implicit) question $Q$.

The notion of disjointness is defined as follows:

(10) Let $Q$ be a question, then $p$ and $p^{\prime}$ are disjoint answers to $Q$ if and only if there is no answer $r$ to $Q$ such that both $p$ and $p^{\prime}$ necessarily entail $r$.

This characterisation proves successful to treat all the cases seen so far.

- As soon as one of the conjuncts entails the other one, the condition of disjointness is violated, and thus and is predicted to be out. This is what happens in (2), and for Elaboration and REFORMULATion relations in general, where the second conjunct entails the first one, and thus cannot be construed as being disjoint from the first.

- For the case of Explanation, it is not the disjointness which proves problematic, but the fact that the conjuncts do not address the same question. In those cases, whatever the question $Q$ that $A$, the first conjunct, answers, the second conjunct $B$ will answer the question Why $A$ ? precisely because an ExPLANATION is targeted.

The Z\&J account is thus more adequate than Txurruka's or the RT approach, since it seems to account for the observations mentioned so far. Nevertheless, the additive account still faces empirical problems. In order to illustrate them, we use the question in (11A) and the set of answers given in $(11 \mathrm{~B})-(11 \mathrm{D})$.

(11) A - Est-ce que Paul va passer l'examen de statistiques? Is Paul going to take the statistics exam?

$\mathrm{B}$ - Il est fatigué et il n'a pas beaucoup révisé. He is tired and has not worked much. 
$\mathrm{C}$ - Je pense qu'il va abandonner, (? et) il n'a pas beaucoup révisé. I think he'll give up, (? and) he has not worked much.

D - Il n'a pas beaucoup travaillé et (donc) je pense qu'il va abandonner.

He has not worked much and (so) I think he'll give up.

To facilitate our exposition, we use the following notations:

- $\alpha=$ "Paul is tired."

- $\beta=$ "Paul has not worked much."

- $\gamma=$ "I think Paul will give up."

In (11B), et/and is felicitously used to connect $\alpha$ and $\beta$. This is expected since they are both disjoint answers to question (11A). In (11C), the use of and to connect $\gamma$ and $\beta$ is infelicitous. Under the additive account, this implies that $\gamma$ and $\beta$ are not disjoint answers to (11A). This does not come as a surprise if $\beta$ entails $\gamma$ when answering (11A). A reviewer rightly points out that $\beta$ does not properly entail $\gamma$. This is a general problem with the Z\&J framework. They use the notion of necessary entailment, which we take to be equivalent to model theoretic entailment $\models, A \models B$ meaning that every model that satisfies $A$ also satisfies $B$. In general, 'entailment' relations between commonsense propositions expressed in natural language seem to be probabilistic and/or non-monotonic. The premises of a given conclusion are not strictly compelling, from a logical point of view. We have two options at this point. Either we retain the original definition of Z\&J and we conclude that $(11 \mathrm{C})$ is in principle possible, since the disjointness criterion, which relies on logical necessity, is not violated, or we assume that the disjointness criterion can be relaxed to exclude cases where a proposition creates somehow a strong expectation that another proposition is true. Let us now consider (11D). Under the logical necessity interpretation of entailment, the answer is predicted to be fine. The problem is then to explain why $(11 \mathrm{C})$ is much less natural. Under the strong expectation interpretation, both answers should come out as anomalous.

A similar problematic observation involves the possibility of having ELABORATION relations introduced by et/and. In (12B), Paul did two things, whereas, in $(12 \mathrm{C})$, the conjunct introduced by and could reformulate the first one. The example would then mean that Paul had a great time watching his movie. This is unexpected under the additive account: if both conjuncts are disjoint answers to the question, (12B) and (12C) should be parallel. 


$$
\begin{aligned}
& \text { A - Qu'a fait Paul? } \\
& \text { What did Paul do? } \\
& \text { B - Il a passé un bon moment et regardé un film. } \\
& \text { He had a great time and watched a movie. } \\
& \text { C - Il a regardé un film et passé un bon moment. } \\
& \text { He watched a movie and he had a great time. }
\end{aligned}
$$

Finally, it must be noted that the problems raised by the two previous examples are also shared by the RT approach presented in the previous section since it gives a symmetric role to each conjunct.

\subsubsection{Taking stock}

We have described a number of empirical problems raised by three different approaches, namely the accounts of Txurruka, RT and Z\&J. Still, we believe that their insights point to the right direction. All of them point to the same characteristic of et/and: in a sentence $A$ et/and $B, A$ and $B$ must not be redundant, and they must play parallel roles. The notions of redundancy and parallelism have to be made precise. This will be the core of the proposal presented in the next section.

\subsection{Our proposal: et/and as a marker of argumentative independence}

To give formal substance to the idea that both et/and-conjuncts must make distinct contributions to a common element, we will start from the argumentative framework proposed by Anscombre \& Ducrot (1983) and developed in probabilistic terms by Merin (1999). Our proposal is close to the one proposed in Winterstein (2010) about et. In order to avoid disrupting the course of the description and analysis, we have confined the presentation of the probabilistic operations used in this paper to the appendix. Suffice it to say that $p \sim_{\mathcal{B}} q$ means that, in the belief state $\mathcal{B}, p$ constitutes 'a reason for believing $q$ ' in Ducrot's terms. In probabilistic terms, this means that assuming that $p$ is true makes the probability of $q$ increases. We discuss more precisely the intended meaning of 'being a better argument' (13c) in the appendix. At this point, it is enough to consider that if we assume $p \& p^{\prime}$, the probability of $q$ rises by a certain amount, which is superior to the amount by which the probability of $q$ rises when we assume $p$ alone.

(13) A discourse of the form $A$ et/and $B$ is felicitous in an epistemic state $\mathcal{B}$ with respect to a conclusion $C$, iff. $A, B$ and $C$ express propositions $p, p^{\prime}$ and $q$ such that: 
a. $\quad p \sim \mathcal{B} q$

b. $p^{\prime} \leadsto \mathcal{B} q$

c. In $\mathcal{B}, p \& p^{\prime}$ is a better argument for $q$ than $p$ alone.

(13c) imposes the following situation.

\begin{tabular}{llll}
\hline \multirow{2}{*}{ Scenarios } & Initial probability of $q=Q_{1}$ & Assume $p$ alone & New probability of $q=Q_{2}$ \\
\cline { 2 - 4 } & Initial probability of $q=Q_{1}$ & assume $p$ and $p^{\prime}$ & New probability of $q=Q_{3}$ \\
\hline Constraints & $Q_{1}<Q_{2}, Q_{1}<Q_{3}, Q_{2}<Q_{3}$ \\
\hline
\end{tabular}

In other terms, the two conjuncts of et/and must be arguments for the same conclusion, and the second argument must still carry some probabilistic weight once the first one has been accepted. Suppose that we add $p \& p^{\prime}$ and that $p^{\prime}$ does not add anything to $p$ with respect to $q$. In that case, the probability of having $q$ would not be superior to what it would have been if we had added only $p$ and the constraint $Q_{2}<Q_{3}$ in the previous table would not be satisfied.

One must note that (13) allows for the case where $q$ is simply the conjunction of $p$ and $p^{\prime}, p \& p^{\prime}$. In that case, both conjuncts must be independently necessary to get the conclusion. For instance, if we assume that $p$ and that $p \Rightarrow p^{\prime}$, we get $p, p \Rightarrow p^{\prime} \vdash p \& p^{\prime}$, where ' $\vdash$ ' notes logical deduction. Although this deduction is logically correct, it does not satisfy constraint (13c), since $p^{\prime}$, being entailed by $p$, is unnecessary and does not add anything. This effect does not extend to a probabilistic dependence of $p^{\prime}$ on $p$, as explained in the appendix.

Like the previous ones, this description of et/and immediately takes care of the cases where the second conjunct logically follows from the first. This account also leaves room for cases of ELABORATION and REFORMULATION (i.e. cases where the first conjunct is entailed by the second) as long as the second conjunct can have some argumentative weight on the goal defended by the first conjunct.

When the two conjuncts are perfectly independent regarding some goal, it is also predicted that the order in which they are presented is irrelevant, since the knowledge of either one does not affect the potential effects of the other. This is the case of the examples in (14) (suggested by a reviewer), which can be reordered by switching the conjuncts around.

A - What are the main cities in Germany? 
B - Frankfurt is the main financial center and Berlin the main cultural center.

In (14), each segment gives a piece of information that is independent from the other, and each contributes to the overall goal corresponding to the conjunction of the contents of each conjunct.

It is also worth noting that the case of (1a) gets a different interpretation depending on what goal is assumed for the coordination. Out of the blue, the Result/Consequence interpretation appears to be dominant. However, if one explicitly suggests a different kind of goal, this preference disappears. For example, if one asks "What happened at the airport?" an ENUMERATION reading is more salient, and the RESULT reading gets backgrounded, if it is present at all. This is explained by the fact that, in the context of this explicit question, the overall goal for which the coordination argues is merely the coordination of the two conjuncts.

In the rest of this section, we show how our proposal applies to the problematic cases seen so far. We also show how it comes about that et/and seemingly blocks some discourse relations. For clarity, we group the different examples that have been mentioned in previous sections into distinct subsets, corresponding to the discourse relations of SDRT (Asher \& Lascarides, 2003). We then discuss a potential issue for our account, involving the specific case of correction.

We distinguish three cases of discourse relations summarised in table (15). We focus on the relations that appear prima facie to be problematic for the case of and.

\begin{tabular}{ll}
\hline Discourse relations & Where to find typical examples \\
\hline EXPLANATion & $(1 \mathrm{~b}),(2 \mathrm{~b}),(3),(5),(11)$ \\
\hline ELABORATion & $(2 \mathrm{a}),(12)$ \\
\hline CONSEQUENCE/RESUlt & $(1 \mathrm{a}),(8 \mathrm{~b}),(24)$ \\
\hline
\end{tabular}

We do not mean to say that the use of and is incompatible with other discourse relations. For example, and is compatible with a "mirative" reading in (16), where the speaker expresses some measure of outrage/surprise (this example is discussed among others by Blakemore \& Carston (2005)).

(16) Her husband is at the hospital, and she's seeing other men. 
In (16) the use of but, an explicit marker of opposition, would have been possible, and would not have carried the mirative component. We do not think that our analysis has much to offer in this regard since it can be argued that the mirative reading arises from the comparison between and and but. The surprise reading comes from the fact that both events hold at the same time, even though one should not expect the second given the first. Using but marks this unexpectedness, which prevents or weakens the surprise reaction. By using and, the speaker does not mark unexpectedness and each conjunct may then be seen as an argument for a conclusion such as "Both $A$ and $B$ hold", from which the element of surprise can be pragmatically derived.

\subsubsection{Explanation}

We first show why et/and is not compatible with an explanation relation. ${ }^{4}$ If two discourse segments with contents $\alpha$ and $\beta$ are linked by an ExPLANATION relation, this translates as follows in the argumentative perspective:

- $\beta$ must be conducive to $\alpha: \beta \leadsto \mathcal{B} \alpha$

- The conclusion targeted by the assertion of the content $\beta$ corresponds to the content $\alpha$.

This characterisation of ExPLANATION entails that $\beta$ is evaluated in an epistemic context to which $\alpha$ has not already been added, otherwise $\beta$ could have no effect on the probability of $\alpha$. This is precisely what an explanation is about: one states his conclusion, before giving an argument to believe it, so belief is suspended until the argument is given, even though $\alpha$ was already uttered before. The fact that $\alpha$ was uttered does not automatically entail that it is added right away to the common ground. The point of an EXPLANATION is to give the addressee sufficient grounds for making this move. More generally, an argumentative goal is supposed not to be part of the common ground beforehand.

The argumentative interpretation of EXPLANATION is in direct conflict with the formalisation of et/and given in (13):

- et/and imposes that both conjuncts share their targeted conclusions.

- Explanation imposes that the second conjunct target the first.

- Therefore the first conjunct must target itself.

- The constraints of et/and compare the respective argumentative effects

\footnotetext{
${ }^{4}$ As noted by a reviewer, (5) sounds like a direct counter-example to this claim. We show below that the structure of (5) is in fact different from what it seems to be.
} 
of $\alpha$ and $\alpha \& \beta$.

- It is then impossible for $\alpha \& \beta$ to be a better argument than $\alpha$ for the conclusion $\alpha$ : the second conjunct cannot add anything in this regard since $\alpha$ is maximally argumentative for itself.

In the case of $(1 \mathrm{~b})$, blocking the ExPLANATION reading amounts to implying that the second event cannot account for the first. Whether the two events are independent or the first causally determines the second is then a matter of context and commonsense knowledge.

The formalisation given in (13) also straightforwardly accounts for the differences between (11C) and (11D).

- The conjunct $\beta$ (Paul has not worked much) does not entirely settle the question Is Paul going to take the statistics exam?, even though it argues for a negative answer. This can be seen in (17) where the whole utterance gives a positive answer to the question and in which the discourse marker mais ( $\simeq$ but in English) marks the argumentative opposition between its conjuncts (Winterstein, 2010).

(17) Paul n'a pas beaucoup révisé, mais il va passer l'examen quand même.

Paul has not worked much, but he will take the exam anyway.

- Thus, once $\beta$ has been asserted, it is still possible to coordinate it with a more decisive conjunct, for example $\gamma$ (I think Paul will give up). The use of and is then predicted to be felicitous.

- If $\gamma$ is asserted first, the question is entirely solved and adding $\beta$ cannot add anything else in this regard. It is thus correctly predicted that and is not felicitous to connect $\gamma$ and $\beta$.

A potential issue is raised by the example given in (5): the use of because unambiguously marks an EXPLANATION, and its use is combined with and. To solve this problem, we adopt Jayez (2004)'s analysis of because:

- The content marked by because belongs to the main content of its host utterance (unlike markers like but that place it at an implicated level).

- The structure of an utterance of the form $A$ and it's because $B$ is thus equivalent to $A$ and the cause of $A$ is $B$.

- The segment the cause of $A$ is $B$ is not conducive to $A$ by itself: it is to be understood as a consequence relation from $B$ to $A$, but does not include information about the status of $B$, even though because $B$ does entail $B$, although not as a main content. Therefore just knowing 
about the consequence without knowing about $B$ is not sufficient to raise the probability of $A$ in this case.

- This leaves room for finding a conclusion $C$ that is common to both conjuncts and allows the use of and. Given the context, such a conclusion could be, for instance, "the sanitary situation is really something of a scandal". This also means that the relation of ExPLANATION is set up between the left segment and a sub-constituent of the right conjunct (and not the whole right conjunct). Specifically, in (5):

- The Explanation relation is between Measles is back and Your kids aren't vaccinated (= the sub-constituent which is an argument of It's because...)

- The argumentative constraints bear on the first conjunct and the main content of the whole second conjunct, i.e. The cause of the Measles being back is your kids not being vaccinated.

Finally, note that excluding ExPLANATION is also effective in confining French en effet to its CONFIRMATION reading when it is combined with et (cf. the case of (3)).

\subsubsection{Elaboration}

ElABORATION is in principle compatible with et/and in our account. Since (12C) is supposed to answer a question about Paul's occupations, the goal targeted by $(12 \mathrm{C})$ can be assumed to be just the conjunction of the events of Paul watching the movie and getting fun. Since the fact that Paul had a good time watching the movie is really an addition to the fact that he watched the movie, the conditions for et/and are satisfied and the answer is predicted to be fine. With $(12 \mathrm{~B})$, the order of constituents is reversed and the second constituent $(\beta)$ can be interpreted as explaining the first $(\alpha)$. We saw that this is not an appropriate context for et/and, which accounts for the tendency to separate the two events, as noted in section 2.2.3.

This leaves us with cases like (2a). One can construct many examples of the same type, for instance (18a-b). If they are understood as simple descriptions, answering questions like Did Paul buy a car or a motorbike? and What did Paul do yesterday?, these examples are not very natural.

a. Paul a acheté une voiture (? et) c'est un vieux modèle.

Paul bought a car (? and) it's an old model. 
b. Paul a visité un chateau (? et) il datait du 14ème siècle. Paul visited a castle (? and) it dated back to 14 th century.

It is interesting to contrast (18) with (19a-b), which are more natural.

a. Paul a acheté une voiture (et) il a choisi un vieux modèle.

Paul bought a car (and) he chose an old model.

b. Paul a visité un chateau (et) il a appris qu'il datait du 14ème siècle.

Paul visited a castle (and) he learned that it dated back to the 14 th century.

We conjecture that this difference comes from the fact that the second sentence in (18a-b) is not a normal way of addressing the mentioned questions, as suggested by the clumsiness of the B1 versions of the following dialogues.

A - Did Paul buy a car or a motorbike?

$\mathrm{B} 1$-? The car he bought is an old model.

B2 -He chose an old car model.

A - What did Paul do yesterday?

$\mathrm{B} 1$-? The castle he visited dates back to the 14 th century.

$\mathrm{B} 2$-He learned that the castle he visited dates back to the 14 th century.

It is well-know that answering a question by means of a presupposition is in general an infelicitous discourse move (see Grimshaw 1979, 321 for a first explicit formulation and Jayez 2010; Simons et al. 2010; Amaral et al. 2011; Jayez 2011 for more recent discussions). Because the second sentence in (18ab) exploits a presupposition to address the question under discussion, it does not constitute a totally felicitous answer. However, (13) requires that both conjuncts be possible arguments towards a given goal, which is not the case in the examples under consideration.

A reviewer observes that there might be an effect of the non-congruence between the question and the answer. This seems very plausible, given that in (18), the second conjuncts do not seem to contain much information relevant to Paul. It is unclear how the age of the car or of the castle could affect Paul in any way. While we agree that 'aboutness' is the main descriptive factor here, we try to account for the reason why there is (in)congruence in the first place. The reviewer objects to the possible role of presupposition in this 
respect that answer B2 in (21) presuppposes that Paul visited a castle. So, if presupposition was what prevents congruence to obtain, it should have a negative effect here also. However, it is claimed in Jayez (2010), on the basis

of experimental evidence, that the actual constraint on the possibility for a presupposition to address a question is as in (22).

(22) An expression containing a main content and a presupposition cannot enter certain discourse relations (including question-answer pairs) through the presupposition alone. The main content must play a role.

For instance it is natural for a speaker to say Paul has a strong will because he stopped smoking, implying that both the main content (Paul doesn't smoke) and the presupposition (he has been smoking) are relevant to the conclusion that Paul has a strong will. In contrast, it would sound weird to say Paul has stopped smoking because he liked that, if the meaning to be conveyed is that Paul smoked because he liked that. In that case, the speaker tries to force an attachment to the presupposition alone. We find the same configuration in B1 of (20) or (21). In B2 of (21), however, the main content is about Paul and the answer is then congruent with the question. So we see that, in the examples at hand, aboutness is determined by the main content vs. presupposed status of the piece of information that addresses the question. This said, it is quite likely that other aspects of meaning affect aboutness.

\subsubsection{Consequence}

So far, we have only briefly mentioned the relation of CONSEQUENCE. Carston (1993), borrowing data from Bar-Lev \& Palacas (1980) notes that and cannot be used to mark a logical consequence, whereas it is fine with a non-necessary consequence (what Carston calls a causal consequence).

In the framework we use, one can see the relation of CONSEQUENCE as marking that $p$, the content of the first conjunct, is relevant to $p^{\prime}$, the content of the second conjunct. Therefore when the two conjuncts stand in a configuration such that the first appears highly conducive to the second, the goal that is used for the interpretation of and can be the second conjunct itself, as long as $p$ does not monotonically entail $p^{\prime}$. In that case, whatever goal is defended, $p^{\prime}$ could not have argumentative effects on its own anymore. In example (1a), a non-necessary CONSEQUENCE relation is present between the conjuncts, and this allows the whole coordination to be interpreted as an argument for the second conjunct alone. Of course, as said earlier, this 
relation can be backgrounded if an explicit question changes the goal that the speaker wants to defend (cf. the discussion of (1a) on p.14).

Let's now turn to examples that involve an explicit marker of ConsEQUENCE and discuss the fact that this marker appears sometimes necessary with and.

First, observe that in (23), a CONSEQUENCE relation can be inferred between the two conjuncts of an asyndetic coordination without the use of an explicit marker such as donc/so, although a specific intonation might be required in the case of $(23 \mathrm{a}) .{ }^{5}$ In both cases an explicit marker can also be used.

a. Paul a [un berger allemand $]_{i}$, (donc) il a [un chien $]_{i}$.

Paul has a German shepherd, (so) he has a dog.

b. Paul a regardé un film indien, (donc) il a passé un bon moment. Paul watched an indian movie, (so) he had a good time.

Using an and-coordination slightly alters this landscape: in (24a), the use of a bare coordination is not possible anymore and it is necessary to use a CONSEQUENCE marker to convey this relation (otherwise one might understand that Paul has two dogs).

a. Paul a [un berger allemand $]_{i}$, et \# (donc) il a [un chien $]_{i}$.

Paul has a German shepherd, and so he has a dog.

b. Paul a regardé un film indien, et (donc) il a passé un bon moment. Paul watched an Indian movie, and so he had a good time.

As already said, the explanation for that follows from the fact that when the second conjunct is a logical consequence of the first, as in (24a), all its potential effects are already part of the effect of the first conjunct. In other terms, the second conjunct cannot add anything to the conclusion targeted by the first conjunct. This does not hold anymore if the consequence is not a necessary one as in (24b).

There remains the question of why (24a) improves when using an explicit

\footnotetext{
${ }^{5}$ The specific contour we allude to is located at the end of the second conjunct, on chien $(d o g)$ in our example. It is classified as a rising +falling contour and is called intonation d'implication. Whereas its spectrum of interpretations is still a matter of debate, it is clear that one of its uses is to signal that a certain piece of information is obvious but might be overlooked by the addressee (see Portes (2004)).
} 
CONSEQUENCE marker? One way of accounting for this is that the speaker wants to remind the addressee that having a German shepherd entails having a dog. For example, take the context in (25), suggested by a reviewer, where (24a) appears perfectly felicitous.

A - Paul does not have a dog.

B - Well, he has a German shepherd and so he has a dog.

In this setting, $B$ 's answer comes as a denial of $A$ 's claim, i.e. its final goal is essentially to argue for the second conjunct itself. One way of analyzing $B$ 's denial is that he first presents a non-controversial statement, and then uses a CONSEQUENCE marker to underline the fact that the first conjunct is conducive to the second, i.e. that to admit that one has a German shepherd entails to admit that the same person has a dog. In other terms, $B$ presents the addressee as possibly unaware of the connection. Since it is very unlikely that the addressee is actually not aware of the consequence relation, one might think that the speaker just pretends to remind the addressee of the connection, as suggested by a reviewer. The speaker might use this strategy in order to present the proposition that Paul has a dog as a mere matter of reasoning rather than an empirical fact, always open to revision and dispute.

This example shows that, generally speaking, a form A et/and B may mechanically raise the probability of the conjunction $p \& p^{\prime}$ and argue simultaneously for a goal different from the conjunction. ${ }^{6}$

\subsubsection{Correction}

In Jasinskaja (sub.), the argumentative take on et/and is being questioned in the light of the possibility of using et/and to mark a CORRECTION:

Paul est allé à Berlin, et pas à Paris.

Paul went to Berlin, and not to Paris.

Jasinskaja contends that the argumentative account can deal with (26). The main argument is that in (26), the argumentative goal defended by the first conjunct is "Paul went to Berlin" which prevents the second conjunct to have any effect on this goal.

In order to apply the argumentative analysis, we need to come up with an argumentative goal that is consistent with the conditions on the use of

\footnotetext{
${ }^{6}$ We return to this possibility in section 3.1 and refine the notion of 'argumentation'.
} 
et/and. One such goal is given by the second conjunct: "Paul was not in Paris". The first conjunct does argue for this goal insofar as one considers that being in Paris decreases the chances to be in Berlin at some other time. And of course the second conjunct also argues (in a most definitive manner) for the same goal.

So, at this stage, we merely want to point out that the argumentative take on et/and takes care of the correction readings, under the assumption that the right goal is constructed. The issue then boils down to determining how the argumentative goal is constructed. Even though the question is an interesting and challenging one, it goes far beyond the scope of our study. The interested reader can read more about this problem in (Winterstein, 2010).

\section{De plus and d'ailleurs}

\subsection{Main properties}

De plus is very similar to the English moreover or in addition. As many sentential adverbs in French it can be found in initial, median and final position. It has a variant, en plus, which we ignore here, because it is not significantly different from de plus with respect to the aspects we discuss in this section. ${ }^{7}$

The easiest way to grasp the main properties of de plus is to compare it to et. We will argue that the de plus differs from et by adding a supplementary constraint according to which the argumentative goal $q$ defended by each conjunct must be different from the conjunction of the two conjuncts.

The first observation is that the CONSEQUENCE/RESUlT interpretation is harder to get with de plus than with et, although it is not completely ruled out. In the counterpart of (1) with de plus, the dominant intuition is that the two events are independent. Neither constituent can express a consequence or a cause of the other and both versions of (27) appear synonymous.

a. Paul a oublié son passeport. De plus, il a été bloqué à la frontière par la police.

Paul forgot his passport. DE PLUS, he was blocked at the frontier by the police.

\footnotetext{
${ }^{7}$ Other additive markers, such as en outre, par surcrôt, or de surcrôtt are associated with a more formal register. They will not be studied here either.
} 
b. Paul a été bloqué à la frontière par la police. De plus, il a oublié son passeport.

Paul was blocked at the frontier by the police. DE PLUs, he forgot his passport.

However, as announced, de plus is not entirely incompatible with RESULT or CONSEQUENCE. If there is some common argumentative goal, distinct from each conjunct and that the constituents connected by de plus can target, the examples are in general more natural, as illustrated by (28) where the segment including de plus gives another argument for the fact that Paul had problems going to France. Even though this second argument is a consequence of the first, it is presented as a different problem, and thus a supplementary argument. (28b) refers to the decision of French government to increase taxes on selling one's second home. According to the author of the text, this move will impede real estate transactions, leading to a decrease on the amount of money that taxes on the latter type of transaction yield. This will make it more difficult for local communities to make ends meet. The logical structure is thus as follows:

reform $\Rightarrow$ less transactions $\Rightarrow$ (a) less taxes on transactions for local communities $\Rightarrow$ (b) budgeting problems for local communities

(28) a. Paul a eu un certain nombre de problèmes quand il est allé en France. Il avait perdu son passeport. Du coup, il a de plus été bloqué à la frontière par la police.

Paul had a number of problems when going to France. He had lost his passport. DU COUP he was DE PLUS blocked at the frontier by the police.

b. Au final, [cette réforme] va donc en plus mettre en péril les finances des collectivités locales qui vont devoir augmenter leurs taxes locales.

Ultimately, [this reform] is going DONC EN PLUS to endanger the budget of local communities, which will have to increase the local taxes.

http://www.latribune.fr/vos-finances/immobilier/transaction/ 20111007trib000654922/reforme-des-plus-values-immobilieres-troissolutions-pour-reduire-la-facture.html

In contrast, it is not possible to connect by de plus two constituents A and $\mathrm{B}$ such that $\mathrm{B}$ is a strict consequence of $\mathrm{A}$. The epistemic reading mentioned 
in section 2.3.3 cannot rescue de plus. (29) is marginally understandable (without the donc) only under an interpretation where having a dog is a supplementary argument for a targeted goal, which entails that Paul has at least two dogs, a German shepherd and another dog and that-rather surprisingly-the speaker does not consider a German shepherd to be a dog.

\# Paul a un berger allemand, (et) (donc) de plus il a un chien.

Paul has a German shepherd (and) therefore DE PLUs he has a dog.

These remarks suggest that the difference between et and de plus resides in the nature of the targeted goal. With $\mathrm{A}$ et $\mathrm{B}$, the goal can be simply the $\mathrm{A} \& \mathrm{~B}$ conjunction, as we noted in section 2.3. With de plus the goal must be common to $\mathrm{A}$ and $\mathrm{B}$ (like with et) but must be distinct from the mere conjunction A \& B. This explains why de plus is frequently odd in a pure factual conjunctive answer. The de plus version of (30) is strange because it implies the existence of a goal different from the simple conjunction of information pieces about the two capitals.

$$
\begin{aligned}
& \text { A - Quelles sont les capitales de l'Angleterre et de la France? } \\
& \text { Which are the capitals of England and France? } \\
& \text { B - Londres est la capitale de l'Angleterre et/??de plus Paris est la } \\
& \text { capitale de la France. } \\
& \text { London is the capital of England and/DE PLUS Paris is the cap- } \\
& \text { ital of France. }
\end{aligned}
$$

In some cases, where the conjunction A \& B constitutes the question under discussion, using de plus conveys the impression that the speaker targets another goal, different from the conjunction. So, in (31), B's answer is interpreted as meaning that the conjunction of the two facts that Paul speaks Chinese and knows China well is relevant to a goal beyond this conjunction.

$$
\begin{aligned}
& \text { A - Est-ce que Paul parle le Chinois et connaît bien la Chine? } \\
& \text { Does Paul speak Chinese and know China well? } \\
& \text { B - Oui, il parle le Chinois, (et) de plus il connaît bien la Chine. } \\
& \text { Yes, he speaks Chinese. (and) DE PLus he knows China well. }
\end{aligned}
$$

Intuitively, the function of de plus is to signal that an additional argument is introduced with respect to some goal. If $\mathrm{A}$ and $\mathrm{B}$ are just elements of a NARRATION or EnUmeration, de plus is not appropriate unless it points to some other goal in addition to $\mathrm{A}$ and $\mathrm{B}$. 
Finally, consider (32). The argumentative target is the same as in (28), that is the different problems of Paul when going to France. Yet, the result is much more awkward than for (28).

?? Paul had a number of problems when going to France. He was blocked at the frontier by the police. EN EFFET, DE PLUS he had lost his passport.

De plus is subject to the same restriction as et/and. It is not compatible with an explanation relation, for the reasons mentioned in section 2.3.1. With $p$ en effet, de plus $q$, the contribution of $q$ is null since $p$ is already introduced in the belief state of the speaker.

\subsection{Representation}

The representation for de plus is the same as for et with one major complication. With et, the goal can be any proposition whose probability is affected by the conjuncts, including the proposition expressed by A et $\mathrm{B}$. With de plus, the goal must remain distinct from A \& $\mathrm{B}$. It is not necessarily a question under discussion, though. In fact, there are three different cases.

(a) The goal is explicitly introduced before A (33a).

(b) The goal is explicitly introduced after A $(33 \mathrm{~b}, \mathrm{c})$.

(c) The goal is not explicitly introduced (33d).

(33) a. Paul ne va pas pas se présenter à son examen. Il n'a pas travaillé, de plus il est malade.

Paul is not going to sit for the exam. He didn't work, DE PLUS he is ill.

b. Paul n'a pas travaillé. (Donc) il ne va pas se présenter à son examen. De plus il est malade.

Paul didn't work. (So) he is not going to sit for the exam. DE PLUS he is ill.

c. Paul n'a pas travaillé, de plus il est malade. (Donc) il ne va pas se présenter à son examen.

Paul didn't work, DE PLUS he is ill. (So) he is not going to sit for the exam.

d. Paul n'a pas travaillé, de plus il est malade.

Paul didn't work, DE PLUS he is ill. 
All these examples have in common that the speaker produces Paul didn't work and Paul is ill as arguments in favour of the proposition that Paul is going to give up his exam or some other unidentified proposition (33d). In (33a,c) using et instead of de plus would not make a substantial difference. In (33d), de plus forces an 'argumentative' interpretation, which cannot be reduced to just asserting the two propositions.

Accordingly, the constraint for de plus is formulated as in (34), where condition (c) is the only novel part when compared with constraint (13).

A discourse of the form $A$ de plus $B$ is felicitous in an epistemic state $\mathcal{B}$ with respect to a conclusion $C$ iff. $A, B$ and $C$ express propositions $p, p^{\prime}$ and $q$ such that:

a. $\quad p \leadsto \mathcal{B} q$

b. $p^{\prime} \leadsto \mathcal{B} q$

c. $q \neq p \& p^{\prime}$

d. In $\mathcal{B}, p \& p^{\prime}$ is a better argument for $q$ than $p$ alone.

Concerning the fact, noted above for (29), that de plus cannot connect a proposition and one of its strict consequences, even when a consequence marker is added, it can be accounted for as follows. (34) entails that the second conjunct $\left(p^{\prime}\right)$ cannot be the argumentative target. If it were the case, one would have $p \sim_{\mathcal{B}} p$ (by definition of $\sim_{\mathcal{B}}$ ) and $p \sim_{\mathcal{B}} p^{\prime}$, which gives $p \sim_{\mathcal{B}} p \& p^{\prime}$, that is, the case explicitly prohibited in $(34 \mathrm{c})$.

\subsection{A short note on D'ailleurs}

This section will be brief because the main technical problems have been addressed in sections 2, 3.1 and 3.2. It does not aim at providing a complete description but rather at illustrating some possible extensions of the ideas that we have been presenting in the last two sections on et and de plus. We refer the reader to Ducrot et al. (1980) and Paillard \& Kisseleva (1999) for more extensive descriptions.

D'ailleurs is the composition of de and ailleurs ('elsewhere') (see for instance http://atilf.atilf.fr/tlf.htm). Depending on the context, the intuitive meaning of the adverb can often be paraphrased by moreover or by the way. The first substantial description of d'ailleurs was proposed in (Ducrot et al., 1980, chap. 6) where it is definitely treated as an argumentative element. Ducrot's description goes as follows: a form "A d'ailleurs B" targets a goal $G$ such that (i) A and B both target $G$ (coorientation) 
and (ii) B is presented as a supplementary and non-necessary argument. For instance, (35), an example from Ducrot et al. (1980) means that the price of the room is an argument for not renting it. The tastes of the speaker are an additional argument, but the price would suffice to motivate her negative decision.

(35) Je ne veux pas louer cette salle. Elle est trop chère. D'ailleurs elle ne me plaît pas.

I don't want to rent this room. It is too expensive. D'AILLEURS I don't like it.

In order to support their claim about the sufficient character of A, Ducrot et al. (1980) note that d'ailleurs is incompatible with expressions that 'program' the occurrence of $\mathrm{B}$, for instance enumeration markers.

(36) \# Je n'assisterai pas à la réunion. Premièrement, Je n'ai pas envie d'y aller. Deuxièmement, elle sera d'ailleurs sûrement annulée.

I won't attend the meeting. First, I don't feel like going there. Second, it will D'AILLEURS certainly be cancelled.

In spite of its interest, this analysis is problematic for two reasons. First, in configurations of the form "C, A d'ailleurs B", it seems difficult to prove that $\mathrm{A}$ is really intended by the speaker to be a 'sufficient' argument. The following discourse is not incoherent and implies that A (Paul is not always pleasant) is not a sufficient reason for $\mathrm{C}$ (the speaker's dislike).

(37) Je n'aime pas beaucoup Paul. Déjà (mais ça ne suffirait pas, bien sûr), il n'est pas toujours aimable. D'ailleurs les autres au bureau ne l'aiment pas beaucoup non plus.

I don't like Paul very much. For one thing (but it wouldn't be enough, of course), he is not always pleasant. D'AILLEURS the other guys in the office don't like him much either

If $\mathrm{A}$ is not a sufficient argument for $\mathrm{C}$, how come that enumerations are not felicitous with d'ailleurs, as observed by (Ducrot et al., 1980), see (36)? In fact, a possible answer to this question derives from the second problem with the analysis proposed there. Paillard \& Kisseleva (1999) cast doubt on the possibility for an argumentative analysis to capture all the relevant features of d'ailleurs. In a nutshell, their idea is that, in at least some cases, d'ailleurs does not introduce an 'argument' proper but a piece of information that is 
unrelated to the argumentative main target, contrary to what Ducrot et al. (1980) claim. If Paillard and Kisseleva are right, d'ailleurs disrupts the argumentative flow, making thus impossible to construct a coherent enumeration of arguments.

Can one decide who is right? We claim that both analyses are basically correct, when the range of cases where they apply is more carefully delineated. When it modifies a parenthetical or an appositive, d'ailleurs may function as an Elaboration marker, see (38a). This is more difficult when it introduces the main sentence, see (38b), although not impossible, see (38c) ${ }^{8}$ The difference between (38b) and (38c) seems to be due to a difference between the two Elaboration moves. Specifically, in (38b), the fact that Paul got a new car is not relevant to any natural concern about Paul. In a neutral context, people are normally not concerned about the cars of other people. In contrast, the sentence is more natural when it echoes a previous conversation about whether Paul has got a new car. In (38c), the fact that Paul is in good shape addresses a natural concern about others' health.

a. J'ai vu Paul, qui d'ailleurs a changé de voiture, et je lui ai demandé pour le projet.

I met Paul, who D'AILlEuRs has got a new car, and I asked him about the project.

b. \# J'ai vu Paul. D'ailleurs il a changé de voiture. Je lui ai demandé pour le projet.

I met Paul. D'AILlEURS he has got a new car. I asked him about the project.

c. J'ai vu Paul. D'ailleurs il est en pleine forme. Je lui ai demandé pour le projet.

I met Paul. D'AILlEuRs he is in top shape. I asked him about the project.

So d'ailleurs can be a pure ElABORATION marker, with no special argumentative import, when it modifies peripheral information (see Potts (2005) for a general introduction), and can in general introduce at least certain types of Elaboration.

To see what the effect of d'ailleurs is in the configuration studied in

\footnotetext{
${ }^{8}$ Somewhat symmetrically, Ducrot et al. (1980) noted that d'ailleurs is infelicitous in restrictive relative clauses.
} 
Ducrot et al. (1980), let us look at (39). (39b) is odd, unless the speaker is considered as an expert for the type of problem mentioned in the discourse. This example and similar ones suggest that a form "A d'ailleurs B" presents $\mathrm{B}$ as an argument that makes $\mathrm{A}$ dispensable with respect to the goal $\mathrm{C}$ under consideration, the proposition that the problem was too difficult, in the case at hand.

a. Le problème était trop difficile. Je n'ai pas trouvé la solution. D'ailleurs personne ne l'a trouvée.

The problem was too hard. I didn't find the solution. D'AILLEURS nobody found it.

b. \# Le problème était trop difficile. Personne n'a trouvé la solution. D'ailleurs je ne l'ai pas trouvée.

The problem was too hard. Nobody found the solution. D'AILLEURS I didn't find it.

So, d'ailleurs does two things in one pass. (1) It introduces an extra argument (B) for a certain goal $\mathrm{C}$, like et and de plus. (2) it signals that this argument does not combine with some other argument (A) to add plausibility to the target, but rather that the net effect of conjoining arguments (A \& B) is not superior to the effect of using $\mathrm{B}$ alone, with respect to the probability of $\mathrm{C}$.

(40) A discourse of the form $A$ d'ailleurs $B$ is felicitous in an epistemic state $\mathcal{B}$ with respect to a conclusion $C$ iff. $A, B$ and $C$ express propositions $p, p^{\prime}$ and $q$ such that:

a. $p \leadsto \mathcal{B} q$

b. $p^{\prime} \sim_{B} q$

c. In $\mathcal{B}, p \& p^{\prime}$ is not a better argument for $q$ than $p^{\prime}$ alone.

This characterisation makes more precise the intuition expressed by (Ducrot et al., 1980, p. 198) that, in a structure "C, A d'ailleurs B", B must constitute an 'independent argument'. We see independence as a side-effect of the fact that the truth of first argument, A, does not affect the efficacy of the second. (40) also allows us to explain the impossibility of using d'ailleurs in an enumeration of arguments (see (36)). Such an enumeration normally accumulates arguments towards a common goal. If one of these arguments makes one of the others useless, why should the latter be mentioned at all in the first place?

We conclude that the landscape of d'ailleurs is probably less uniform than 
suggested by previous work. The marker can introduce an ELABORATION, in parentheticals, but also convey a dependence interpretation, like et and de plus. It is tempting to see the profile of d'ailleurs as a more or less direct reflection of its etymology (lit. 'from elsewhere'), which seems to imply some form of semantic or pragmatic discrepancy, but we are still wanting a serious diachronic study in order to evaluate this perspective.

\section{Conclusion}

In this paper, we have provided a survey of various cases of additivity in French, highlighting the role of probabilistic (in)dependence and the way in which different discourse markers impose different constraints on it. In the final section, we have explored some routes to an analysis of d'ailleurs. In all the cases under review, it turns out that lexicon informs discourse structure, or in other terms that the conventional implicatures associated with discourse markers filter out the discourse configurations that do not satisfy the implicatures or do so at the cost of very implausible inferences. There are many open questions that the present paper suggests but does not answer. We will mention only two of them. First, it is not clear what the limits of a probabilistic approach are. It proved convenient for the markers studied here, but it remains to be seen for instance whether it would be sufficient for studying the whole range of additive markers. We saw, for example, that d'ailleurs can mark ELABORATION without any special probabilistic value. Second, as we already noted in the introduction, the study of discourse markers seems to lead us beyond a traditional Gricean analysis, because the semantic code on which pragmatic strategies operate can hardly be considered as logically 'minimal'. This departure from Grice is not so surprising, given that, in retrospect, the techniques and theoretical tools available to linguists and philosophers in the seventies borrowed heavily from a simplified philosophical version of classical logic. When one takes a step back from this traditional view, it is not so obvious that and should be \&, or $\vee$ or if $\Rightarrow$, if only because the range of formal tools has significantly widened in the last forty years and, as a result, the possibility of expressing complex lexical constraints has increased. It remains to be seen how a richer conception of lexicon squares with a Gricean approach. 


\section{Appendix A.}

In this section we discuss the notion of relevance used in the paper. Intuitively, some piece of information $p$ is relevant to some other distinct piece $q$ if learning that $p$ can modify our beliefs about $q$.

In the paper we have opted for a probabilistic presentation. At the abstract level we consider, what we need is simply an ordering relation between situations. For instance, if I realise that there are big black clouds in the sky, saying that it 'reinforces' my belief that it will rain means that, other things being equal, the situations where it rains in some appropriately near future are ranked higher on some scale than the situations where it does not rain. If we need to implement this preference relation, any model that allows us to capture a hierarchy between descriptions of states of affairs is in principle admissible. Such models include in particular non-monotonic and probabilistic logics, see Makinson (2005) for a unified presentation. So, probabilistic approaches are among plausible candidates for representing commonsense inference, but they are not demonstrably superior to other approaches.

However, it turns out that, in more specific cases, non-monotonic rules are much less appealing that probabilities. Consider (41).

$$
\begin{aligned}
& \mathrm{A}-\text { Is Paul the tallest boy in the family? } \\
& \mathrm{B}-\text { He is tall, but less than his brother. }
\end{aligned}
$$

In Anscombre and Ducrot's classic analysis, but signals that the left and the right constituents point to opposite argumentative goals (see Winterstein (2010) for a defence of this claim). With (41), if we assume that the goal is the proposition that Paul is not the tallest boy in the family, we have to explain how it is possible for He is tall to constitute an argument for the proposition that Paul is the tallest boy in the family. We are certainly not going to make up a non-monotonic rule according to which to be tall entails by default to be taller than other members of one's family. This is a general problem with gradual predicates or adverbs. Non-monotonic systems have been devised for inferences between propositions and are difficult to apply to degree properties. In contrast, a probabilistic treatment readily extends to such cases. The intuition is that to be tall means to be taller than a certain threshold. When a proposition of the form ' $x$ is tall' is introduced in a belief state, it eliminates all possibilities (situations, possible worlds, etc.) in which $x$ is less tall than the threshold. Assuming some measure on sets of possibilities, the proportion of possibilities where Paul is the tallest boy 
can only increase, after the information that Paul is tall has been added to the belied state. More precisely, let $t$ be the threshold of tallness and $t^{\prime}$ be the size of the tallest boy in the family. When we introduce size $(x)>t$, we have two options. (1) If $t^{\prime} \leq t$, obviously $\operatorname{size}(x)>t^{\prime}$. (2) If $t<t^{\prime}$, we eliminate those possibilities in which size $(x) \leq t$ and they are all possibilities in which size $(x)<t^{\prime}$. In both cases, the proportion of cases where $x$ is inferior or equal to $t^{\prime}$ ( $=x$ is not the tallest boy in the family) decreases. What we have here is the core of the probabilistic analysis of argumentation, a reasoning on measures, not on rules. Its main interest lies in its flexibility: it covers practically all scenarios for supporting a conclusion, including those that exploit degrees.

The relation between argumentation, probability and belief is familiar from Arthur Merin's work (Merin, 1999). Merin's approach is Bayesian, which means that the belief dependency is analysed as a conditional probability. Let $\mathcal{B}$ be a belief state. $\operatorname{Pr}_{\mathcal{B}}(q)$ denotes the probability of $q$ in $\mathcal{B}$. $\mathcal{B} \oplus p$ denotes the effect of learning $p$ on $\mathcal{B}$. Merin posits (42), which says that the probability of $q$ after learning $p$ and only $p$ in $\mathcal{B}$ is the probability of $q$ conditioned on $p$ in $\mathcal{B}$.

$$
\operatorname{Pr}_{\mathcal{B} \oplus p}(q)=\operatorname{Pr}_{\mathcal{B}}(q \mid p)
$$

The effect of (42) is to align updates on conditional probabilities. The standard model that implements this correspondence is modal, that is, it uses a set of information points (situations, worlds) as its basic ontology. Probability is defined as a measure over this set.

For a set of formulas $F$, the sample space is any set of (entirely defined) situations $S$ that, if $s \in S, s \models A$ or $s \models \neg A$ for every $A \in F$ (= completeness of the situations). We define a probability to be a probabilistic measure on the powerset of $S$.

Given (42), Merin's definition of relevance is based on a the contrast between the effects of learning a proposition. Intuitively, $E$ (evidence) is relevant to $H$ (hypothesis) if learning $E$ makes $H$ more probable than its contrary $\neg H$, i.e. in other terms: $\operatorname{Pr}_{\mathcal{B} \oplus E}(H)>\operatorname{Pr}_{\mathcal{B} \oplus E}(\neg H)$. Contrasts between the effects of updates can be evaluated as differences or as quotients. Quotients are usually preferred in probabilistic approaches because they yield proportions (e.g. 0.4 is twice 0.2). Moreover, Merin prefers logarithms of quotients in order to capture the intuition that relevance is null whenever there is no gain 
or loss in probability.

The relevance of $E$ to $H$ in $\mathcal{B}, r_{B}^{\mathcal{H}}(E)$, is $\log \left[\operatorname{Pr}_{\mathcal{B}}(H \mid E) / \operatorname{Pr}_{\mathcal{B}}(\bar{H} \mid E)\right]$.

In order to define the argumentative relation between a goal and an argument, we need to clarify the dynamic sequence of belief states. Let us consider a pair of sentences like Paul is tired. He has been working very hard, assuming that it conveys an ExPLANATION. If the proposition that Paul is tired $(=q)$ is considered as a fact by the speaker, we cannot say that the proposition that Paul has been working very hard $(=p)$ makes the probability of $q$ increase. Moreover, it might be the case that $p$ is also considered to be a fact. In other terms, just before the sentences are uttered, nothing prevents $p$ and $q$ to be true in the belief state of the speaker. In this respect, we cannot just define relevance as the increase of the probability of $q$ when one adds $p$ to this belief state. The general problem of defining reasonable update conditions for probabilistic belief systems is notoriously unclear and difficult (Huber, 2009). However, one can adopt a less ambitious perspective and consider that $p$ is relevant to $q$ in a belief state $\mathcal{B}$ just in case $\mathcal{B}$ contains information such that, for every belief state $\mathcal{B}^{\prime}$ containing this information, making the probability of $p$ increase in $\mathcal{B}^{\prime}$ makes that of $q$ increase or decrease simultaneously. It is not necessary that the information that guarantees the relevance of $p$ to $q$ be certain in $\mathcal{B}$. In fact, certain propositions may have a very low probability because they represent counteracting factors. For instance, in a context where Paul is tired because he is ill and the effect of having been working very hard is not significant, the probabilistic dependence of interest (working hard $\leadsto$ being tired) does not obtain. So, it might be important that the probability of Paul being ill is very low.

We also need a notion of update, analogous to what is done in dynamic semantics. We consider only the following simple version, assuming the $\oplus$ operation is deterministic. In more complex approaches, one has to make room for the possibility that the relevant proposition is set to a value superior to a certain threshold, but not necessarily to 1 , and that the probability adjustment delivers several new belief states.

$$
\begin{aligned}
& \mathcal{B} \oplus p \text { is the result of setting the probability of } p \text { to } 1 \text { in } \mathcal{B} \text {. } \\
& p \leadsto \mathcal{B} q={ }_{\mathrm{df}} \exists \Phi \forall \mathcal{B}^{\prime}\left(\forall \phi \in \Phi ( \operatorname { P r } _ { \mathcal { B } ^ { \prime } } ( \phi ) \approx \operatorname { P r } _ { \mathcal { B } } ( \phi ) ) \Rightarrow \left(\operatorname{Pr}_{\mathcal{B}^{\prime} \oplus p}(q)>\right.\right. \\
& \left.\left.\operatorname{Pr}_{\mathcal{B}^{\prime}}(q)\right)\right)
\end{aligned}
$$

Definition (46) says that $p$ is conducive to $q$ in $\mathcal{B}$ whenever $\mathcal{B}$ contains in- 
formation that guarantees that assuming $p$ will make the probability of $q$ increase. Applied to (13), the definition entails that $\mathcal{B}$ contains information that guarantees that assuming $p$ or $p^{\prime}$ in a belief state where the same information holds with the same probability makes the probability of $q$ increase.

We finally need to express the differential effect of $p$ and $p$ plus $p^{\prime}$.

(47) We say that $p$ is a better argument than $p^{\prime}$ for $q$ with respect to $\mathcal{B}$ whenever $\exists \Phi \forall \mathcal{B}^{\prime}\left(\forall \phi \in \Phi\left(\operatorname{Pr}_{\mathcal{B}^{\prime}}(\phi) \approx \operatorname{Pr}_{\mathcal{B}}(\phi)\right) \Rightarrow\left(\operatorname{Pr}_{\mathcal{B}^{\prime} \oplus p}(q)>\right.\right.$ $\left.\left.\operatorname{Pr}_{\mathcal{B}^{\prime} \oplus p^{\prime}}(q)\right)\right)$.

Given (47), (13c) mean that $p \& p^{\prime}$ is a better argument for $q$ than $p$ alone. When $p \Rightarrow p^{\prime}(13 \mathrm{c})$ is violated because $\mathcal{B}^{\prime} \oplus p=\mathcal{B}^{\prime} \oplus\left(p \& p^{\prime}\right)$ for any $\mathcal{B}^{\prime}$ and, as a result, $\operatorname{Pr}_{\mathcal{B}^{\prime} \oplus\left(p \& p^{\prime}\right)}(q)=\operatorname{Pr}_{\mathcal{B}^{\prime} \oplus p}(q)$. Suppose now that $p \sim_{\mathcal{B}} p^{\prime}$ but $p \not p^{\prime}$. In that case, it is possible that $\operatorname{Pr}_{\mathcal{B}^{\prime} \oplus\left(p \& p^{\prime}\right)}(q)>\operatorname{Pr}_{\mathcal{B}^{\prime} \oplus p}(q)$. We will illustrate this possibility by means of the following example.

The initial belief state, $\mathcal{B}$, contains the following information.

1. For $p=$ 'Paul worked late', $\operatorname{Pr}_{\mathcal{B}}(p)>\ell_{1}$, where $\ell_{1}$ is high.

2. For $p^{\prime}=$ 'He got less sleep than usual', $\operatorname{Pr}_{\mathcal{B}}\left(p^{\prime}\right)>\ell_{2}$, where $\ell_{2}$ is high.

3. $q=$ 'He is tired'.

4. $\operatorname{Pr}_{\mathcal{B}}$ (long work $\Rightarrow$ tired $)>\ell_{3}$, where $\ell_{3}$ is high.

5. $\operatorname{Pr}_{\mathcal{B}}($ long work \& less sleep than usual $\Rightarrow$ tired $)>\ell_{4}$, where $\ell_{4}$ is high.

Given this configuration, it is perfectly possible that:

a. $\forall \mathcal{B}^{\prime}\left(\left(\operatorname{Pr}_{\mathcal{B}^{\prime}}\left(\right.\right.\right.$ long work $\Rightarrow$ tired $\left.\left.>\ell_{3}\right)\right) \Rightarrow \operatorname{Pr}_{\mathcal{B}^{\prime} \oplus \text { long work }}($ tired $)>$ $\operatorname{Pr}_{\mathcal{B}^{\prime}}($ tired $\left.)\right)$

b. $\forall \mathcal{B}^{\prime}\left(\left(\operatorname{Pr}_{\mathcal{B}^{\prime}}\left(\right.\right.\right.$ long work \& less sleep than usual $\Rightarrow$ tired $\left.\left.>\ell_{4}\right)\right) \Rightarrow$ $P r_{\mathcal{B}^{\prime} \oplus \text { long work \& less sleep than usual }}($ tired $)>P \operatorname{Pr}_{\mathcal{B}^{\prime}}($ tired $\left.)\right)$

c. $\forall \mathcal{B}^{\prime}\left(\left(\operatorname{Pr}_{\mathcal{B}^{\prime}}\left(\right.\right.\right.$ long work \& less sleep than usual $\Rightarrow$ tired $\left.\left.>\ell_{4}\right)\right) \Rightarrow$

$P r_{\mathcal{B}^{\prime} \oplus \text { long work \& less sleep than usual }}($ tired $)>P r_{\mathcal{B}^{\prime} \oplus \text { long work }}($ tired $\left.)\right)$

(a) says that, in $\mathcal{B}$, long work is conducive to tired, (b) that long work \& less sleep than usual is also conducive to tired and that long work \& less sleep than usual is a better argument for tired than long work alone.

\section{References}

Patricia Amaral, Chris Cummins and Napoleon Katsos (2010). "Experimental Evidence on the Distinction Between Foregrounded and Backgrounded Meaning". In Gregory Kienstead, Craige RoberTs and Judith 
Tonhauser (Eds.) Proceedings of the ESSLLI 2011 Workshop on Projective Meaning, 1-7.

Jean-Claude Anscombre, Oswald Ducrot (1983). L'argumentation dans la langue. Liège, Bruxelles: Pierre Mardaga.

Mira ARIEl (2008). Pragmatics and Grammar. Cambridge: Cambridge University Press

Nicholas Asher, Alex Lascarides (2003). Logics of Conversation. Cambridge: Cambridge University Press.

Nicholas Asher, Laure VIEU (2005). "Subordinating and coordinating discourse relations". In: Lingua 115, 591-610.

Zev BAR-Lev, Arthur PALACAS (1980). "Semantic command over pragmatic priority". In: Lingua 51, 137-146.

Diane Blakemore, Robyn Carston (1999). "The pragmatics of andconjunctions: the non-narrative cases". In: UCL Working Papers in Linguistics 11, 1-20.

- (2005). "The pragmatics of sentential coordination with and". In: Lingua $115,569-589$.

Robyn CARSTON (1993). "Conjunction, explanation and relevance". In: Lingua 90, pp. 27-48.

Danièle Bourcier, Sylvie Bruxelles, Anne-Marie Diller, Oswald Ducrot, Éric Fouquier, Jean Gouazé, Luc Maury, Thanh Binh Nguyen, Géraldo Nunes, Laurence Ragunet de Saint-Alban, Anna RÉmis, Christine Sirdar-Iskandar (1980). Les mots du discours, Paris: Éditions de Minuit.

Bart Geurts (1999). Presuppositions and Pronouns, t. 3 of Current Research in the Semantics/Pragmatics Interface. Amsterdam: Elsevier.

Jane Grimshaw (1979). Complement selection and the lexicon. In: Linguistic Inquiry 10, pp. 279-326. 
Jerry R. Hobbs, Mark E. Stickel, Douglas E. Appelt and Paul Martin (1993). "Interpretation as abduction". In: Artificial Intelligence 63, pp. $69-142$.

Franz Huber (2009). "Belief and degrees of belief". In: F. Huber and C. Schmidt-Petri (Eds.), Degrees of Belief, Springer, pp. 1-33.

Katja JASINSKAJA (sub.). "Correction by Adversative and Additive markers". submitted for publication.

Jacques JAYEZ (2004). "Presuppositions and pedigrees for discourse markers". In O. Bonami,P. CABredo-HoffHerR (Eds.) Empirical Issues in Syntax and Semantics, 5, 89-110,CNRS.

Jacques JAYEZ (2010). "Projective meaning and attachment". In Maria Aloni, Harald Bastiannse, Tikitu de Jager and Kathrin Schulz (Eds.) Logic, Language and Meaning, LNAI 6042, 325-334, Berlin, Heidelberg: Springer.

Jacques JAYEZ (2011). "Projection and probability". Talk given at the ESSLLI 2011 Workhop on Projective Meaning. http://jjayez.pagesperso-orange.fr/doc/JJ-ESSLLI11.pdf

Ekkehard KöNIG (1991). The Meaning of Focus Particles. A Comparative Perspective. London: Routledge.

Ewald LANG (1984). The Semantics of Coordination. Amsterdam: John Benjamins.

David Makinson (2005). Bridges for Classical to Nonmonotonic Logic. London: King's College Publications.

Arthur Merin (1999). "Information, Relevance and Social Decision-Making". In: L.S. Moss, J. GinzburG, M. DE RIJke (Eds.), Logic, Language, and computation, Stanford:CA: CSLI Publications, t. 2, pp. 179-221.

Denis Paillard, Ksenia Kisseleva (1999). "Les mots du discours: garant et point de perspective". In: Revue de Sémantique et Pragmatique 5, pp. 37-56. 
Livia Polanyi (1985). "A theory of discourse structure and discourse reference". In: Proceedings of the 21st Meeting of the Chicago Linguistics Society, Chicago, Illinois

Christel PorTes (2004). "Prosodie et économie du discours : spécificité phonétique, écologie discursive et portée pragmatique du patron d'implication". PhD thesis, Université de Provence.

Christopher PotTs (2005). The Logic of Conventional Implicatures. Oxford: Oxford University Press.

Susan Schmerling (1975). "Asymmetric Conjunction and Rules of Conversation". In: P. Cole, J. L. Morgan (Éds..), Syntax and Semantics: Vol. 3: Speech Acts, San Diego, CA: Academic Press, pp. 211-231.

Mandy Simons, Judith Tonhauser, David Beaver, Craige Roberts (2010). "What projects and why". In: Proceedings of SALT 20, pp. 309327.

Raj Singh (2008). Modularity and Locality in Interpretation. PhD thesis, Massachusetts Institute of Technology.

Isabel Gomez TXuRRuKa (2003). "The natural language conjunction and". In: Linguistics and Philosophy 26, pp. 255-285.

Grégoire Winterstein (2010). "La dimension probabiliste des marqueurs de discours. Nouvelles perspectives sur l'argumentation dans la langue". PhD thesis, Université Paris Diderot.

Henk Zeevat, Katja Jasinkaja (2007). "And as an additive particle". In: Michel Aurnague, Kepa Korta, Jesus Mari Larrazabal (Eds.), Language, Representation and Reasoning. Memorial volume to Isabel Gómez Txurruka, University of the Basque Country Press, pp. 315-340. 